\title{
Optimal operation of thermal system based on optimum power flow
}

\author{
Majli Nema Hawas', Read K. Ibrahim², Ahmed Jasim Sultan ${ }^{3}$ \\ ${ }^{1,3}$ Middle Technical University, Electrical Engineering Technical College, Iraq \\ ${ }^{2}$ Al-Farahidi University, Department of Medical instruments engineering techniques, Iraq
}

\begin{abstract}
Article Info
Article history:

Received Nov 15, 2019

Revised Feb 6, 2020

Accepted Apr 29, 2021

Keywords:

Economic dispatch Newton-Raphsin technique

Optimal power flow

ABSTRACT

This paper has demonstrated that the Newton-Raphsin (NR) load flow technique can be stretched out to produce optimal load flow (OPF) arrangement that is achievable as for all significant disparity imperatives. These arrangements are frequently desired for arranging and activity. We were examined how the load ought to be shared among different plants, when line misfortunes are represented to limit the absolute activity cost with optimal power flow computation with thought about penalty factors, steady fuel cost, and coefficient factors. The IEEE three-machines and nine- Bus bars system was a tested system. The obtained results were compared by initial operation and equality distribution through the saving cost (\$/year). The comparison of results showed saving more than 1.6 million \$/year under MATLAB V.18a environment.
\end{abstract}

Optimal scheduling

Power system control

This is an open access article under the $\underline{C C B Y-S A}$ license.

\section{Corresponding Author:}

Majli Nema Hawas

Electrical Engineering Technical College

Middle Technical University

Baghdad, Iraq

Email: gnmajli@gmail.com

\section{INTRODUCTION}

The transmission misfortunes may fluctuate from 5-15\% of the complete load, it is fundamental to represent misfortunes while building up a monetary load dispatch arrangement. It will be less expensive to draw more power from the generator which is nearer to the loads. The principle point in the financial dispatch is to limit the complete eighth of generator genuine power at different stations while fulfilling the loads and misfortunes in the transmission lines [1-3]. To start with the economic factor in power system operation, we will focus attention on optimum allocation of generation to each station for various system load level. The transmission loss was expressed in term of B-coefficients [4].

The optimal power flow program (OPF) is utilized to optimize the power flow arrangement of enormous scale power framework. This is finished by limiting chosen objective capacities while keeping up an adequate framework execution as far as generator ability limits and the yield of the repaying capacities, may exhibit financial cost, framework security, or different objectives. Effective reactive power arranging upgrades financial activity just as framework security [5]. The OPF has been examined by numerous analysts and numerous calculations utilizing diverse objective capacities and methods have been displayed [6-8].

\section{MATHEMATICAL MODELING}

\subsection{Transmission loss coefficient}

One of the major steps of the optimal dispatch of generation is to express the system losses in terms of the generator's real power output. 


$$
\begin{aligned}
P_{L} & =P_{G 1}^{T} H P_{G 1}^{*} \\
H & =\left[\begin{array}{cccccc}
B_{11} & B_{12} & \ldots \ldots \ldots & B_{1 n} & B_{o 1} / 2 \\
B_{21} & B_{22} & \ldots \ldots \ldots & B_{2 n} & B_{o 2} / 2 \\
\vdots & \vdots & \ldots \ldots & \vdots & \vdots \\
B_{n g 1} & B_{n g 2} & \ldots \ldots & B_{n g n g} & B_{\text {ong }} / 2 \\
B_{o 1} / 2 & B_{o 2} / 2 & \ldots \ldots & B_{\text {ong }} / 2 & B_{o o}
\end{array}\right]
\end{aligned}
$$

The B-coefficients are elements of the framework working state. In the event that new scheduling of generation isn't radically not quite the same as the underlying working condition, the misfortunes coefficient might be expected steady.

\subsection{Optimal load flow solution method}

The arrangement strategy presented here was initially by Domle and Trinney [3]. It dependent on NR load flow method, a first request angle alteration calculation for limiting the objective capacity and utilization of penalty capacity to represent imbalance requirements on subordinate factors [9-13]. The objective capacity to be limited is the operating cost:

$$
\begin{aligned}
& C=\sum_{i=1}^{n} C_{i} P_{G i} \\
& P_{i}+\sum_{\mathrm{j}=1}^{\mathrm{n}} \mathrm{P}_{\mathrm{Gi}} V_{i} V_{j} Y_{i j} \cos \left(\theta_{i j}+\delta_{i}-\delta_{j}\right)=0 \text { for each PQ bus } \\
& Q_{i}+\sum_{\mathrm{j}=1}^{\mathrm{n}} \mathrm{P}_{\mathrm{Gi}} V_{i} V_{j} Y_{i j} \cos \left(\theta_{i j}+\delta_{i}-\delta_{j}\right)=0 \text { for each PQ bus } \\
& P_{i}-\sum_{\mathrm{j}=1}^{\mathrm{n}} \mathrm{P}_{\mathrm{Gi}} V_{i} V_{j} Y_{i j} \cos \left(\theta_{i j}+\delta_{i}-\delta_{j}\right)=0 \text { for each PQ bus }
\end{aligned}
$$

In (4)-(6) can be expressed in vector form:

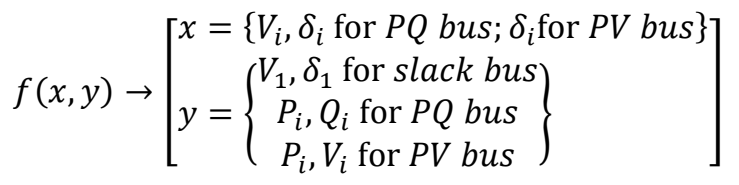

The free factor vector (y) can be apportioned to two sections: the control factor vector (u) which is shifted to accomplish optimum estimation of the target capacity and the vector ( $\mathrm{p}$ ) of fixed or wild parameters. The optimization problem can be restated as [14-16]:

$$
\min _{u} C(x, u)
$$

Subjected to equality constraints:

$$
f(x, u, p)=0
$$

To solve the streamlining issue, characterize the Lagrangian function as:

$$
L(x, u, p)=C(x, u)+\lambda^{T} f(x, u, p)
$$

where $L$ Lagrangian function; $\mathrm{u}$ : Vector of control variables; $\mathrm{x}$ : Vector of dependent variable; $p=$ Vector of uncontrollable variables. functions:

The important conditions to limit the unconstrained Lagrangian function are differentiation of matrix

$$
\begin{aligned}
& \frac{\partial L}{\partial x}=\frac{\partial C}{\partial x}+\left[\frac{\partial f}{\partial x}\right]^{T} \lambda=0 \\
& \frac{\partial L}{\partial u}=\frac{\partial C}{\partial u}+\left[\frac{\partial f}{\partial u}\right]^{T} \lambda=0 \\
& \frac{\partial L}{\partial \lambda}=f(x, u, p)=0
\end{aligned}
$$


In (11)-(13) are nonlinear algebraic equations and it can be solved by iteration.

\section{PROCEDURES OF GRANDIENT METHOD}

The computational strategy for nonlinear logarithmic method with applicable detail is given underneath [17-19]:

a. Make an underlying theory for $\mathrm{u}$, the control factor

b. Locate a possible NR load flow method from (13) iteratively. Its progressively improves the arrangement $\mathrm{x}$ as pursues:

$$
\begin{aligned}
& X^{(r+1)}=X^{(r)}+\Delta X \\
& \Delta X=-\left(j^{(r)}\right)^{-1} f\left(X^{(r)}, y\right.
\end{aligned}
$$

c. Solve (11) for:

$$
\lambda=-\left[\left[\frac{\partial f}{\partial u}\right]^{T}\right]^{-1} \frac{\partial C}{\partial X}
$$

d. Compute the gradient;

$$
\Delta \tau=\frac{\partial C}{\partial u}+\left[\frac{\partial f}{\partial u}\right]^{T} \lambda
$$

e. If equals to the prescribed tolerance then, a minimum value has been reached. Else,

f. Evaluate a new set of control variables:

$$
\begin{aligned}
& u_{\text {new }}=u_{\text {old }}+\Delta u \\
& \Delta u=-\propto \Delta \tau
\end{aligned}
$$

Here $\Delta u$ is the opposite direction step in the gradient:

$$
\begin{aligned}
& u_{\text {min } \leq u \leq} u_{\text {max }} \\
& P_{G i, \text { min }} \leq P_{G i} \leq P_{G i, \text { max }} \\
& u_{i, \text { new }}=\left[\begin{array}{c}
u_{i, \text { max }} \text { if } u_{i, \text { old }}+\Delta u>u_{i, \text { max }} \\
u_{i, \text { min }} \text { if } u_{i, \text { old }}+\Delta u<u_{i, \text { min }} \\
u_{i, \text { old }}+\Delta u \text { if otherwise }
\end{array}\right]
\end{aligned}
$$

The minimization of $L$ undergoing of constraint (21) are:

$$
\frac{\partial L}{\partial u i}\left[\begin{array}{l}
=0 \text { if } u_{i j, \min }<u_{i}<u_{i, \max } \\
\leq 0 \text { if } u_{i}=u_{i j, \max } \\
\geq 0 \text { if } u_{i}=u_{i j, \min }
\end{array}\right]
$$

There, presently, in stage (5) for the computational calculation the inclination vector needs to fulfill the optimum condition (23).

$$
V_{\min } \leq V \leq V_{\max } \quad \text { on PQ bus }
$$

The new objective function becomes:

$$
C^{\prime}=C(X, u)+\sum \omega_{j}
$$

where $\omega_{j}$ is the penalty of each inequality constraint. It can become as: 


$$
\begin{aligned}
& \omega_{j}=\left[\begin{array}{ll}
g_{j}\left(X_{j}-X_{j}, \max \right)^{2} ; & \text { whenever } X_{j}>X_{j}, \max \\
g_{j}\left(X_{j}-X_{j}, \min \right)^{2} ; & \text { whenever } X_{j}>X_{j}, \min
\end{array}\right] \\
& \frac{\partial L}{\partial X}=\frac{\partial C}{\partial X}+\sum_{\mathrm{j}=1}^{\mathrm{n}} \frac{\partial \omega_{j}}{\partial X}+\left[\frac{\partial f}{\partial X}\right]^{T} \lambda=0 \\
& \frac{\partial L}{\partial u}=\frac{\partial C}{\partial u}+\sum_{\mathrm{j}=1}^{\mathrm{n}} \frac{\partial \omega_{j}}{\partial u}+\left[\frac{\partial f}{\partial u}\right]^{T} \lambda=0
\end{aligned}
$$

A decent plan is to begin with a low estimation of $\gamma \mathrm{j}$ and to build it during the streamlining procedure, if the arrangement surpasses a specific resistance limit. This solution is often required for system planning and operation. [20-24].

\section{CASE STUDIES}

An OPF was used for the power framework of Figure 1 to get the optimum activity state for the system to lessen unit cost and resolve the active power flow problem. All details of the information data in appendix A, Table A.1 and A.2 [8, 25].

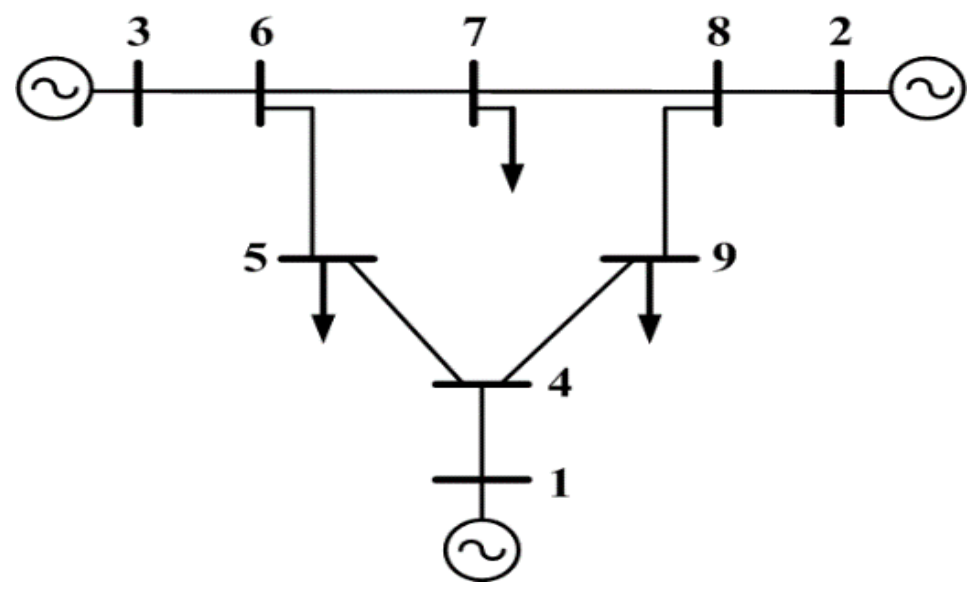

Figure 1. Single line diagram of IEEE 9-Bus power system [20]

\section{RESULTS AND DISCUSSION}

Figure 2 shows the unit gradual operating cost versus unit yield $\mathrm{Pi}$, assume one unit is operating at a higher steady operating cost than different units. Optimal loading of generators corresponds to the equal incremental cost of all generators (8.1) $\$ / \mathrm{MWh}$ to redistribute the power generation of three generators and there is a difference between the origin case, before applying optimal power flow calculation, and the new case, after applying optimal power flow calculation as show in Table 1 . The main advantage of this concept is to know the saving of total operation cost in $(\$ / \mathrm{h})$ or $(\$ /$ year) as shown in Table 2. The total generation cost of the initial condition is $3326.77 \$ / \mathrm{h}$ and the total generation cost with the optimal dispatch is $3515.74 \$ / \mathrm{h}$. This result in a saving of $188.97 \$ / \mathrm{h}$, annually saving $=1655377.2 \$ /$ year. The total generation cost for the equal load distribution between the generation units is $3255 \$ / \mathrm{h}$, this result in a saving of $60.74 \$ / \mathrm{h}$, annually saving $=532082.4$ \$/year as shown in Table 2. At final iteration the B coefficients are as below:

$$
\begin{array}{rlrl} 
& 0.0108 & 0.0011 & -0.0006 \\
\mathrm{~B} & =0.0011 & 0.0308 & -0.0006 \\
& -0.0006 & -0.0010 & 0.0078 \\
\mathrm{~B} 0 & =0.0000143 & 0.0002625 & 0.0000096 \\
\mathrm{~B} 00 & =0.0000014232 &
\end{array}
$$




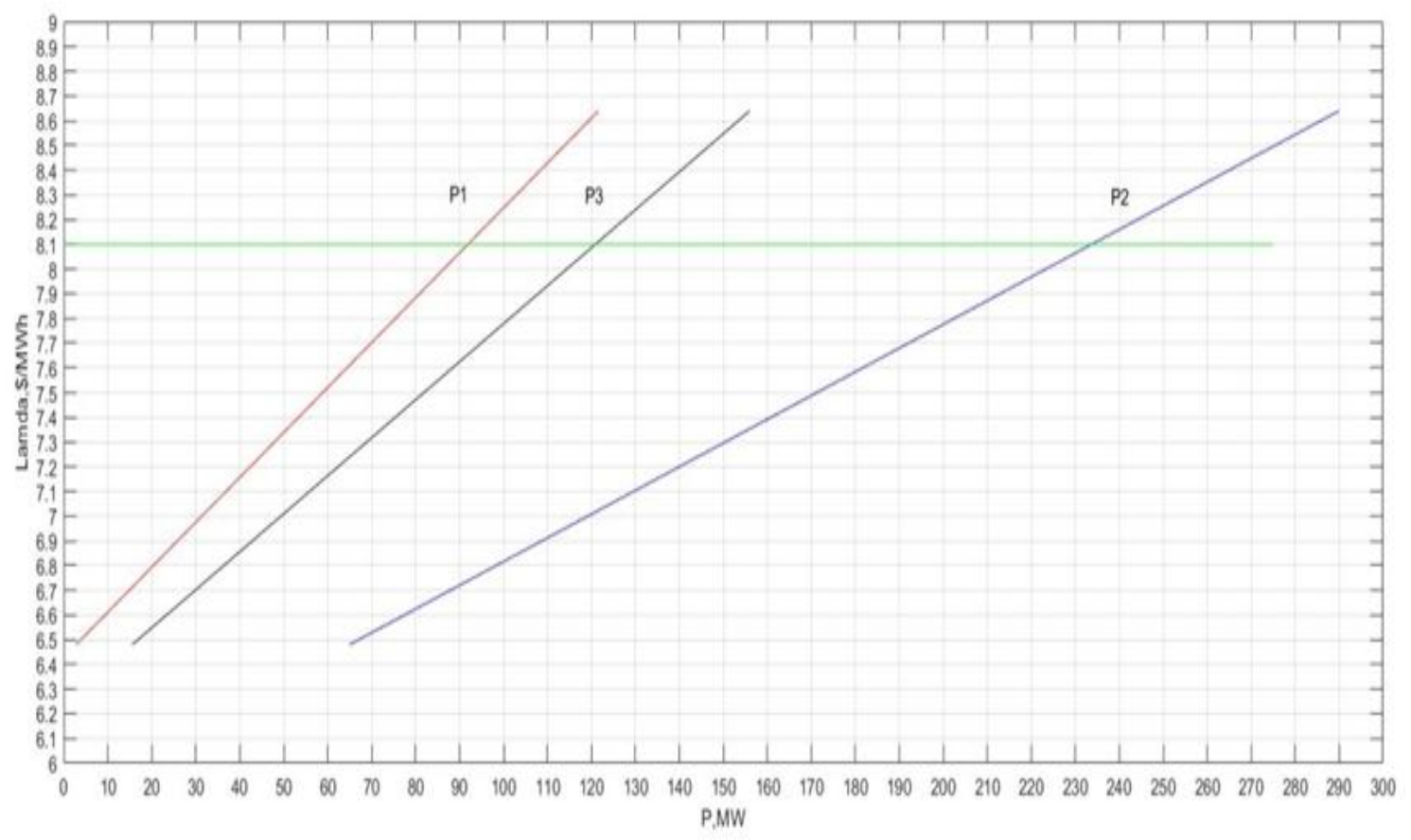

Figure 2. The unit gradual operating cost versus unit yield Pi (MW)

Table 1. Power flow solution by newton-raphson method

\begin{tabular}{cccccccc}
\hline \multirow{2}{*}{ Bus No. } & Voltage & Angle & \multicolumn{2}{c}{ Load } & \multicolumn{2}{c}{ Generation } & Injected \\
\cline { 4 - 7 } & Mag.(P.U) & Degree & MW & Mvar & MW & Mvar & Mvar \\
\hline 1 & 1.040 & 0.000 & 0.000 & 0.000 & 72.145 & 27.245 & 0.000 \\
2 & 1.025 & 11.301 & 0.000 & 0.000 & 163.000 & -6.432 & 0.000 \\
3 & 1.025 & 2.082 & 0.000 & 0.000 & 85.000 & 4.738 & 0.000 \\
4 & 1.004 & -2.759 & 0.000 & 0.000 & 0.000 & 0.000 & 0.000 \\
5 & 0.988 & -4.141 & 90.000 & 30.000 & 0.000 & 0.000 & 0.000 \\
6 & 0.991 & -0.376 & 100.000 & 35.000 & 0.000 & 0.000 & 0.000 \\
7 & 1.010 & 3.637 & 0.000 & 0.000 & 0.000 & 0.000 & 0.000 \\
8 & 1.001 & 5.289 & 0.000 & 0.000 & 0.000 & 0.000 & 0.000 \\
9 & 1.004 & -3.100 & 125.000 & 50.000 & 0.000 & 0.000 & 0.000 \\
& Total & & 315.000 & 115.000 & 320.145 & 25.551 & 0.000 \\
\hline
\end{tabular}

Table 2. Saving with deferent operation methods

\begin{tabular}{ccccccc}
\hline \multirow{2}{*}{ Item } & \multicolumn{2}{c}{ Initial operation } & \multicolumn{2}{c}{ Optimal operation } & \multicolumn{2}{c}{ Equal operation } \\
\cline { 2 - 6 } & $\mathrm{P}_{\mathrm{i}} \mathrm{MW}$ & $\lambda$ \$/MWh & $\mathrm{P}_{\mathrm{i}} \mathrm{MW}$ & $\lambda$ \$/MWh & $\mathrm{P}_{\mathrm{i}} \mathrm{MW}$ & $\lambda$ \$/MWh \\
\hline $\mathrm{P}_{1}$ & 150 & 11.050 & 96.3 & 8.434016 & 117.985 & 6.947 \\
$\mathrm{P}_{2}$ & 80 & 9.400 & 230 & 8.434016 & 117.985 & 8.370 \\
$\mathrm{P}_{3}$ & 120 & 10.390 & 118.8 & 8.434016 & 117.985 & 12.289 \\
Total cost $\$ / \mathrm{h}$ & 3515.74 & 3326.77 & 3455 \\
Saving $\$ / \mathrm{h}$ & -------- & 188.97 & 60.74 \\
Saving $\$ / \mathrm{y}$ & -------- & 1655377.2 & 532082.4 \\
\hline
\end{tabular}

\section{CONCLUSION}

After running OPF the results will appear in Tables 1-2. The total generation cost of the initial condition is $3515.74 \$ / \mathrm{h}$ and the total generation cost with the optimal dispatch is $3326.77 \$ / \mathrm{h}$. Result of saving is $188.97 \$ / \mathrm{h}$. That is, with this loading, the total annual saving is over one million $\$$. In the event that the yield power of that unit is diminished and moved to units with lower steady operating costs, at that point the complete operating cost diminishes. That is, lessening the yield of the unit with higher gradual cost brings about a more prominent cost decline than the cost increment of adding that equivalent yield decreases to units with lower steady costs. Along these lines, all units must work at the equivalent gradual operating costs (the financial dispatch paradigm). 


\section{Appendix A}

Table A.1. Line data

\begin{tabular}{cccccc}
\hline $\begin{array}{c}\text { Bus } \\
\text { NO. }\end{array}$ & Bus & $\begin{array}{c}\mathrm{R} \\
\text { (p.u) }\end{array}$ & $\begin{array}{c}\mathrm{X} \\
(\mathrm{p} . \mathrm{u})\end{array}$ & $\begin{array}{c}1 / 2 \mathrm{~B} \\
(\mathrm{p} . \mathrm{u})\end{array}$ & $\mathrm{F}(\mathrm{Hz})$ \\
\hline 1 & 4 & 0.00 & 0.0576 & 0.000 & 60 \\
2 & 8 & 0.00 & 0.0625 & 0.000 & 60 \\
3 & 6 & 0.00 & 0.0586 & 0.000 & 60 \\
4 & 5 & 0.017 & 0.092 & 0.079 & 60 \\
5 & 6 & 0.039 & 0.170 & 0.179 & 60 \\
6 & 7 & 0.0119 & 0.1008 & 0.1045 & 60 \\
7 & 8 & 0.0085 & 0.072 & 0.0745 & 60 \\
8 & 9 & 0.032 & 0.161 & 0.153 & 60 \\
9 & 4 & 0.010 & 0.085 & 0.088 & 60 \\
\hline
\end{tabular}

Table A.2. Bus data

\begin{tabular}{cccccccc}
\hline \multirow{2}{*}{ Bus } & Bus & $\mathrm{V}$ & \multicolumn{3}{c}{ GENERATOR } & \multicolumn{2}{c}{ LOAD } \\
\cline { 4 - 8 } & type & (p.u) & $\mathrm{P}_{\mathrm{G}}(\mathrm{MW})$ & $\mathrm{Q}_{\min }$ & $\mathrm{Q}_{\max }$ & $\mathrm{P}_{\mathrm{L}}(\mathrm{MW})$ & $\mathrm{Q}_{\mathrm{L}}$ (Mvar) \\
\hline 1 & Slack & 1.04 & 0.0 & -300.0 & 300.0 & 0.0 & 0.0 \\
2 & $\mathrm{PV}$ & 1.025 & 163.0 & -300.0 & 300.0 & 0.0 & 10.0 \\
3 & $\mathrm{PV}$ & 1.025 & 85.0 & -300.0 & 300.0 & 0.0 & 15.0 \\
4 & $\mathrm{PQ}$ & 1.0 & 0.0 & 0.0 & 0.0 & 0.0 & 5.0 \\
5 & PQ & 1.0 & 0.0 & 0.0 & 0.0 & 90.0 & 30.0 \\
6 & PQ & 1.0 & 0.0 & 0.0 & 0.0 & 0.0 & 0.0 \\
7 & PQ & 1.0 & 0.0 & 0.0 & 0.0 & 100.0 & 35.0 \\
8 & PQ & 1.0 & 0.0 & 0.0 & 0.0 & 0.0 & 0.0 \\
9 & PQ & 1.0 & 0.0 & 0.0 & 0.0 & 125.0 & 50.0 \\
\hline
\end{tabular}

\section{REFERENCES}

[1] M. Muslu, "Economic dispatch with environmental considerations: Tradeoff curves and emission reduction rates," Electric Power Systems Research, vol. 71, no. 2, pp. 153-158, 2004, doi: https://doi.org/10.1016/j.epsr.2004.01.009.

[2] J. S. Dhillon and D. P. Kothari, "Economic-emission load dispatch using binary successive approximation-based evolutionary search," IET Generation, Transmission \& Distribution, vol. 3, no. 1, pp. 1-16, January 2009, doi: 10.1049/iet-gtd:20070398.

[3] D. P. Kothari and I. J. Negrath, "Modern power system analysis," Tata McGraw Hill Education Private Limited, 2013.

[4] N. M. Yasin, A. J. Sultan, and A. A. Abdulabbas, "Coordination of generation of multi machine power systems" Journal of Engineering and Applied Sciences, vol. 14, no. 12, pp. 4146-4152, 2019, doi: 10.3923/jeasci.2019.4146.4152.

[5] M. Mekhanet, L. Mokrani, A. Ameur, and Y. Attia, "Adaptive fuzzy gain of power system stabilizer to improve the global stability," Bulletin of Electrical Engineering and Informatics (BEEI), vol. 5, no. 4, pp. 421-429, 2016, doi: https://doi.org/10.11591/eei.v5i4.576.

[6] Danyang Guo, Jilai Yu and Mingfei Ban "Security-Constrained Unit Commitment Considering Differentiated Regional Air Pollutant Intensity" Sustainability, Vol. 10, no. 5, 2018, doi: https://doi.org/10.3390/su10051433.

[7] J. J. Grainger and W. D. Stevenson, "Power system analysis," McGraw-Hill Science/Engineering/Math, New York, 1994.

[8] H. Saadat, "Power system analysis," McGraw-Hill, 1999.

[9] J. D. Glover, M. S. Sarms, and T. J. Overbye "power system analysis \& design," $5^{\text {th }}$ edition Cengage Learning, 2012 .

[10] S. S. S. Sharif, J. H. Taylor and E. F. Hill, "On-line optimal reactive power flow by energy loss minimization," Proceedings of 35th IEEE Conference on Decision and Control, 1996, pp. 3851-3856 vol.4, doi: 10.1109/CDC.1996.577262.

[11] A. Herbig, "On-load flow control in electric power system," Doctoral Dissertation, Department of Electric Power Engineering, Royal Institute of Technology, Stockholm, 2000.

[12] D. Lukman and T. R. Blackbum, "Modified algorithm of load flow simulation for loss minimization in power system," The Australian Universities Power Engineering Conferences, pp. 1-7, 2001.

[13] Hui Zhang, and Pu Li "Application of sparse-grid technique to chance constrained optimal power flow," IET Gener. Transm. Distrib., vol. 7, no. 5, pp. 491-499, 2013, doi: 10.1049/iet-gtd.2012.0269.

[14] Yee Ming Chen and Wen-Shiang Wang, "Economic dispatch with environmental considerations using marginal rate of substitution decision approach," Journal of Quality, vol. 16, no. 2, pp. 109-118, 2009. 
[15] K. Choudhary, R. Kumar, D. Upadhyay, and B. Singh, "Optimal power flow based economic generation scheduling in day-ahead power market," International Journal of Applied Power Engineering, vol. 6, no. 3, pp. 123-132, 2017, doi: 10.11591/ijape.v6.i3.pp124-134.

[16] P. Pujihatma, S. P. Hadi, Sarjiya, and T. A. Rohmat, "Combined heat and power-optimal power flow based on thermodynamic model with associated petroleum and wet gas utilization constraints," International Journal of Electrical and Computer Engineering, vol. 9, no. 1, pp. 42-54, 2019, doi: http://doi.org/10.11591/ijece.v9i1.pp4254.

[17] R. Mudumbai, S. Dasgupta and B. B. Cho, "Distributed control for optimal economic dispatch of power generators: The heterogenous case," 2011 50th IEEE Conference on Decision and Control and European Control Conference, Orlando, FL, USA, 2011, pp. 7123-7128, doi: 10.1109/CDC.2011.6161021.

[18] M. Zarei, A. Roozegar, R. Kazemzadeh, and J. M. Kauffmann, "Two area power systems economic dispatch problem solving considering transmission capacity constraints," World Academy of Science, Engineering and Technology, vol. 9, pp. 147-152, 2007.

[19] D. P. Kothari and K. P. S. Parmar, "A Novel Approach for Eco-Friendly and Economic Power Dispatch using MATLAB," 2006 International Conference on Power Electronic, Drives and Energy Systems, New Delhi, India, 2006, pp. 1-6, doi: 10.1109/PEDES.2006.344286.

[20] S. Prabhakar Karthikeyan, K. Sathish Kumar, A. S. Harissh, I. Jacob Raglend and D. P. Kothari, "A Matlab/GUI based simulation tool to solve load flow program for standard test systems," International Conference on Sustainable Energy and Intelligent Systems (SEISCON 2011), 2011, pp. 456-461, doi: 10.1049/cp.2011.0406.

[21] E. Acha, C. R. Fuerte- Esquivel, H. A. Perez, and C. A. Camacho, "FACTS modeling and simulation in power network," Wiley, England, 2004.

[22] J. F. Dopazo, O. A. Klitin, G. W. Stagg and M. Watson, "An optimization technique for real and reactive power allocation," in Proceedings of the IEEE, vol. 55, no. 11, pp. 1877-1885, Nov. 1967, doi: 10.1109/PROC.1967.6017.

[23] H. W. Dommel and W. F. Tinney, "Optimal Power Flow Solutions," in IEEE Transactions on Power Apparatus and Systems, vol. PAS-87, no. 10, pp. 1866-1876, Oct. 1968, doi: 10.1109/TPAS.1968.292150.

[24] Shuijia Li, Wenyin Gong, Ling Wang, Xuesong Yan, Chengyu Hu, "Optimal power flow by means of improved adaptive differential Evolution" Energy, vol. 198, p. 117314, 2020, doi: https://doi.org/10.1016/j.energy.2020.117314.

[25] T. Jayabarathi, Ramesh V., D. Kothari, and K. Pavan, "Hybrid differential evolution technique for the economic dispatch problems," Journal of Electrical Engineering and Technology, vol.3, no.4, pp. 476-483, 2008, doi: 10.5370/JEET.2008.3.4.476. 